\title{
UCAPAN TERIMA KASIH
}

Ucapan terima kasih dan penghargaan disampaikan kepada para pakar yang telah diundang sebagai Mitra Bestari/Penelaah oleh Majalah Pengkajian Industri dalam Volume 10, No. 1, Tahun 2016. Berikut ini daftar nama pakar yang berpartisipasi :

\begin{tabular}{|l|l|}
\hline Nama & Alamat/Instansi \\
\hline $\begin{array}{l}\text { Agus Suhartono, H.Dr.Ing.Ir. } \\
\text { (Bid.Material) }\end{array}$ & $\begin{array}{l}\text { B2TKS, Kawasan Puspiptek, } \\
\text { Gedung 220 Kawasan PUSPIPTEK, Serpong, } \\
\text { Tangerang, Banten }\end{array}$ \\
\hline $\begin{array}{l}\text { I Nyoman Jujur, Dr., MEng., Ir. } \\
\text { (Bid.Teknik Mesin) }\end{array}$ & $\begin{array}{l}\text { Pusat Teknologi Material, BPPT, } \\
\text { Ged.2 BPPT Lt.22, JI.M.H.Thamrin No 8, } \\
\text { Jakarta 10340 }\end{array}$ \\
\hline $\begin{array}{l}\text { Myrna Ariati, Dr,MS Ir. } \\
\text { Bid. Metalurgi dan Material, }\end{array}$ & Dosen Metalurgi dan Material FT-UI \\
\hline $\begin{array}{l}\text { Sulistijono, Prof.Dr.Ir. DEA } \\
\text { (Bid.Teknik Material Desain) }\end{array}$ & $\begin{array}{l}\text { Fakultas Teknologi Industri, Kampus ITS, } \\
\text { Sukolilo, Surabaya }\end{array}$ \\
\hline $\begin{array}{l}\text { Maizirwan Mel, Dr. MSc. } \\
\text { (Bid. Bio Process Engineering) }\end{array}$ & IIUM Gombak-Kuala Lumpur \\
\hline
\end{tabular}




\section{Kata Pengantar}

Majalah Pengkajian Industri Volume 10 No.1 April 2016 kembali menampilkan edisi dengan topik Industri Teknologi Proses, Rekayasa dan Manufaktur. Industri proses, rekayasa dan manufaktur meliputi aneka industri dengan beragam teknologi yang mengolah bahan baku menjadi bahan jadi (produk) sehingga mempunyai nilai tambah. Pengolahan bahan baku tersebut melalui beberapa tahap yang dapat meliputi simulasi proses, desain proses dan desain peralatan dengan mempertimbangkan secara tekno-ekonomi dan dampak terhadap lingkungan. Untuk dapat menjawab tuntutan kemajuan dalam industri proses, rekayasa dan manufaktur diperlukan inovasi dalam bentuk kajian,penelitian dan kerekayasaan.

Terbitan Majalah IImiah Pengkajian Industri volume. 10 No. 1 April 2016 ini, ditampilkan publikasi beberapa penelitian, kajian perekayasaan dan manufactur diantaranya tentang, Identifikasi Bahan Kelongsong Paduan ZrNbMoGe Hasil Uji Hidridasi $400^{\circ} \mathrm{C}-1$ jam Menggunakan Teknik Difraksi, Pengaruh Jacketing pada Kelayakan Operasional Proses Column Distilasi. Pemanfaatan Teknik HEM untuk Penumbuhan CNT dari Grafit Menggunakan Ni sebagai Katalis, Pengaruh Jarak dan Pola Prefabricated Vertical Drain (PVD) pada Perbaikan Tanah Lempung Lunak dan Desain dan Simulasi Tungku Bakar untuk Pengolahan Pasir Besi menjadi Sponge Iron dengan Teknologi Tunnel Kiln Serta Kajian Peran Riset dan Pengembangan dalam Mendukung Industri Kakao Nasional dan Kajian Teknologi Proses Pembuatan Gas Sintetiki dari Batubara dan Prospek Pemanfaatan pada Industri Hilirnya. Redaksi selalu berusaha melakukan perbaikan-perbaikan dalam rangka meningkatkan mutu dan kualitas Majalah IImiah Pengkajian Industri. Selanjutnya Redaksi berencana menerbitkan kembali Vol. 10 No. 2, bulan Agustus 2016 dengan Topik "Indutri Teknologi Trabsportasi". Redaksi sangat menghargai kritik dan saran yang membangun.

Redaksi 


\section{Majalah Pengkajian Industri}

- Identifikasi Bahan Kelongsong Paduan ZrNbMoGe Hasil Uji Hidridasi $400^{\circ} \mathrm{C}-1$ jam Menggunakan Teknik Difraksi (Parikin, bandriyana, A.H.Ismoyo)

- Strategi Peningkatan Mutu Keamanan Produk Kakeri Industri Kecil Menengah Melalui Penerapan Good Manufacturing Practices (GMP) (Himawan Adinegoro)

- Kajian Peran Riset dan Pengembangan dalam Mendukung Industri Kakao Nasional (Lamhot P. Manalu)

- Pengaruh Jacketing pada Kelayakan Operasional Proses Column Distilasi (M.N. Seyia Nusa)

- Pemanfaatan Teknik HEM untuk Penumbuhan CNT dari Grafit Menggunakan Ni sebagai Katalis (Yunasfi, P. Purwanto dan Mashadi)

- Pengaruh Jarak dan Pola Prefabricated Vertical Drain (PVD) pada Perbaikan Tanah Lempung Lunak (Wimpie Agoeng Nugroho Aspar, Eka Nur Fitriani)

- Desain dan Simulasi Tungku Bakar untuk Pengolahan Pasir Besi menjadi Sponge Iron dengan Teknologi Tunnel Kiln (Barman Tambunan, Cuk Supriyadi, Yuliansyah)

- Kajian Teknologi Proses Pembuatan Gas Sintetiki dari Batubara dan Prospek Pemanfaatan pada Industri Hilirnya, (Muslim Efendi Harahap, Endro Wahju Tjahjono) 


\title{
IDENTIFICATION ON ZrNbMOGe ALLOY OF $400^{\circ} \mathrm{C}-1$ HOUR HYDRIDATION TEST FOR CLADDING MATERIALS BY USING DIFFRACTION TECHNIQUE
}

\author{
Parikin, Bandriyana and A.H. Ismoyo
}

\begin{abstract}
Synthesis of a new niobium containing zirconium alloy of $\mathrm{ZrNbMoGe}$ has been developed in PSTBM-BATAN. In PWR/PHWR reactor, this materials face with liquid coolant i.e. $\mathrm{H} 2 \mathrm{O}$ demin that may trig a reaction between hydrogen and containing zirconium. Hydridation tests in argon atmospheer were recently carried out looking for hydrogen effect in material. Hydrogenisation must be avoided due to causing brittle of the material via blistering of $\mathrm{Zr}-\mathrm{H}$ compound system. Sample with $2 \% \mathrm{Nb}, 0.5 \% \mathrm{Mo}, 0.5 \% \mathrm{Ge}$ and $\mathrm{Zr}$ in balance content has been hydridized by flowing $\mathrm{H} 2$ at temperature of $400 \mathrm{oC}$ for an hour. Effects of the test by time-high temperatur dependence on the zirconium content were investigated by $X$-ray diffractometer. The observed peak at $2 \theta=20.95^{\circ}$ was mathematically interpolated by orde- 2 polynomial regression. Identifying peak was performed by X-ray diffraction technique and then it conformed 'search and match' by JCPDS tracing. Results show that new phase in $400 \mathrm{oC}-1$ hour hydridation sample was close to crystal structure of $\varepsilon-\mathrm{ZrH} 2$. The crystallographic data emphasize that new phase with lattice parameter of $a=$ $b=3.52 \AA$ and $c=4.45 \AA$ (tetragonal) is (201) plane or $2 \theta=21.60^{\circ}$. Also, the JCPDS traces another new orthorhombic phase of $\mathrm{Nb3} 33 \mathrm{O} 9$ at angle of $2 \theta=20.91^{\circ}$ with lattice parameter of $a=9.183 \AA, b=22.47 \AA$ and $c=4.24 \AA$ conforming to (220) plane. Hypothesized, this is an anti-hydride layer (passivity) that can overcome hydridation process of cladding materials in the reactor.
\end{abstract}

Keywords : diffraction techniques, ZrNbMoGe alloy, high temperature, hydridation

\section{STRATEGI PENING KATAN MUTU KEAMANAN PRODUK BAKERI INDUSTRI KECIL MENENGAH MELALUI PENERAPAN GOOD MANUFACTURING PRACTICES (GMP)}

\author{
Himawan Adinegoro
}

\begin{abstract}
Abstrak
Tujuan penelitian ini adalah menyusun strategi peningkatan mutu keamanan produk bakeri pada industry kecil menengah melalui penerapan praktek pengolahan terbaik (GMP). Metoda yang digunakan dalam penelitian ini adalah analisa SWOT. Analisa SWOT merupakan salah satu alat analisis kualitatif yang digunakan untuk mengidentifikasi peluang dan ancaman dalam melakukan kegiatan dengan mengacu pada kekuatan dan kelemahan yang dimiliki stakeholders industri kecil menengah produk bakeri di kota Bogor. Penggunaan teknik Interpretive Structural Modeling (ISM) pada analisis SWOT untuk melihat hubungan kontekstual antar elemen dan hirarki untuk elemen penyusun strategi. Hasil analisis dari ke dua model (analisis SWOT dan ISM) dalam penelitian ini adalah strategi terbaik dengan keterbatasan ahli dalam rangka peningkatan mutu keamanan produk bakeri berdasarkan GMP.
\end{abstract}

Kata kunci : Penerapan praktek pengolahan terbaik, analisis SWOT, ISM, Industri kecil menengah bakeri 


\title{
KAJ IAN PERAN RISET DAN PENGEMBANGAN DALAM ME NDUKUNG INDUSTRI KAKAO NASIONAL
}

\author{
Lamhot P. Manalu
}

\begin{abstract}
Abstrak
Kakao merupakan komoditas perkebunan penghasil devisa terbesar ketiga setelah kelapa sawit dan karet. Pada tahun 2012 produksi kakao tercatat sebesar 833.310 ton dengan rata-rata pertumbuhan sebesar 1,56\%. Ada dua tantangan utama dalam pengembangan industri kakao nasional yaitu peningkatan kuantitas (produksi dan produktifitas) dan kualitas. Untuk mendukung usaha tersebut peran riset dan pengembangan (risetbang) sangat dibutuhkan untuk memastikan prosedur yang diterapkan sudah tepat dan sesuai. Studi ini bertujuan untuk mempelajari peran risetbang serta faktor pendukung lainnya dalam menjawab permasalahan kakao nasional. Studi ini berupa hasil survey terhadap responden (pelaku risetbang kakao) yaitu lembaga penelitian dan pengembangan, universitas serta industri pengolahan kakao. Hasil kajian menunjukkan bahwa permasalahan industri kakao nasional terdapat pada semua aspek, dimana aspek budidaya merupakan permasalahan terbesar. Aspek berikutnya adalah penyuluhan, kelembagaan, skala usaha, mutu, kebijakan, pengolahan produk antara dan pengolahan produk hilir. Studi juga menunjukkan bahwa masih banyak hasil riset yang tidak dapat dimanfaatkan oleh industri kakao skala besar, sisanya walaupun telah bersifat aplikatif tetapi hanya untuk skala kecil sehingga kurang signifikan. Pada industri usaha skala kecil dan menengah umumnya peralatan yang digunakan berkapasitas rendah sehingga tidak efisien.
\end{abstract}

Kata kunci : kakao, produksi, riset, pengembangan, budidaya, pengolahan

\section{PENGARUH J ACKETING PADA KELAYAKAN OPERASIONIL PROSES COLUMN DISTILASI}

\author{
M. N. Setia Nusa
}

\begin{abstract}
Abstrak
Column distilasi telah beroperasi selama 42 tahun, beberapa kali mengalami kebocoran di dinding tray bagian atas dan setiap kali repair dilakukan dengan jacketing dan patching. Pada saat ini masih ditemukan ada beberapa kerusakan/kebocoran juga pada tray atas, untuk itu perlu dilakukan penelitian untuk tindakan repair dan mengetahui kondisi terkini column melalui pemeriksaan fraktografi, metalografi, uji kekerasan, komposisi kimia, ketebalan dan pundit sehingga secara keseluruhan hasilnya dapat mengetahui penyebab kerusakan dan mengetahui pengaruh patching dan jacketing pada material. Hasil penelitian ditemukan adanya unsur korosi serta kondisi jacketing yang sudah merata pada bagian atas coulumn destilasi.
\end{abstract}

Kata Kunci : Column, Korosi, Bocor, J acketing 


\title{
PEMANFAATAN TEKNIK HEM UNTUK PENUMB UHAN CNT DARI GRAFIT MENGGUNAKAN Ni SEBAGAI KATALIS
}

\author{
Yunasfi, P. Purwanto dan Mashadi
}

\begin{abstract}
Abstrak
Pemanfaatan teknik HEM (High Energy Milling) untuk penumbuhan CNT (carbon nanotube) dari serbuk grafit dengan menggunakan $\mathrm{Ni}$ sebagai katalis. Proses milling dilakukan terhadap campuran serbuk grafit dan serbuk nikel (serbuk Ni-C) dengan perbandingan berat $98 \%: 2 \%$, dengan variasi waktu milling antara $25-75$ jam. Karakterisasi menggunakan fasilitas PSA (Particle Size Analyzer), SAA (Surface Area Analyzer), dan TEM (Transmission Electron Microscope) serta Raman Spektroscopy yang masing-masing untuk mendapatkan informasi ukuran partikel, luas permukaan dan morfologi serta struktur ikatan serbuk hasil milling. Hasil analisis serbuk Ni-C dengan PSA dan SAA menunjukkan ukuran partikel paling kecil dan luas permukaan paling besar diperoleh setelah proses milling selama 50 jam, masing-masing $80 \mathrm{~nm}$ dan $705 \mathrm{~m}^{2} / \mathrm{g}$. Pengamatan TEM menunjukkan serbuk-serbuk berbentuk serat pipih dengan kuantitas yang meningkat dengan bertambahnya waktu milling. Serat pipih ini perupakan cikal bakal penumbuhan CNT. Serbuk Ni-C hasil milling menunjukkan penumbuhan CNT terlihat lebih jelas setelah milling selama 50 jam. Hasil analisis dengan Raman Spectroscopy memperlihatkan puncak G band pada bilangan gelombang $1582 \mathrm{~cm}^{-1}$ yang merupakan spektrum untuk struktur $\mathrm{sp}^{2}$ dari grafit dan puncak $\mathrm{D}$ band pada bilangan gelombang $1350 \mathrm{~cm}^{-1}$ yang mungkin merupakan deformasi struktur grafit. Posisi puncak G band mendekati $1600 \mathrm{~cm}^{-1}$ menjadi bukti perubahan ke grafit nano kristal. Intensitas $\mathrm{D}$ band tertinggi ditunjukkan oleh sistem komposit $\mathrm{Ni}-\mathrm{C}$ hasil proses milling selama 50 jam dan hal ini sebagai indikasi bahwa proses milling selama 50 jam terhadap sistem komposit Ni-C lebih berstruktur mirip grafit (graphitic-like material) dibanding kondisi lainnya dan diprediksi bagus untuk menumbuhkan CNT. Dengan demikian, waktu milling yang optimal untuk penumbuhan CNT dari serbuk grafit dengan menggunakan Ni sebagai katalis adalah adalah 50 jam.
\end{abstract}

Kata kunci : Grafit, CNT, Teknik Milling, Katalis Ni.

\section{PENGARUH J ARAK DAN POLA PREFABRICATED VERTICAL DRAIN (PVD) PADA PERBAIKAN TANAH LEMPUNG LUNAK}

\author{
Wimpie Agoeng Noegroho Aspar, dan Eka Nur Fitriani
}

\begin{abstract}
Abstrak
Ketika suatu struktur karena alasan-alasan teknis, ekonomi, sosial, atau strategis terpaksa didirikan di atas tanah lunak, maka biasanya ada dua masalah geoteknik yang harus dipecahkan yaitu daya dukung yang rendah dan penurunan serta beda penurunan yang besar. Prakompresi adalah suatu proses pemampatan tanah pondasi dengan jalan pemberian pembebanan sementara (prabeban/preloading) sebelum konstruksi yang sesungguhnya didirikan. Pre-fabricated vertical drain (PVD) adalah sistem drainase buatan yang dipasang vertikal di dalam lapisan tanah lunak. Kondisi tanah di lokasi kegiatan relatif sangat lunak dengan koefisien konsolidasi relatif sangat tinggi mengakibatkan proses konsolidasi berjalan relatif sangat lama. Untuk itu diperlukan perbaikan tanah terlebih dahulu dengan prealoading menggunakan PVD. Jarak spasi antar PVD yang dipasang bervaiasi yaitu $50 \mathrm{~cm}, 100 \mathrm{~cm}, 150 \mathrm{~cm}$, dan $200 \mathrm{~cm}$ dengan pola konfigurasi segitiga dan segiempat. Berdasarkan hasil perhitungan secara analitis didapatkan jarak optimum PVD untuk mencapai konsolidasi $90 \%$ adalah $150 \mathrm{~cm}$ dengan pola segitiga dengan proses konsolidasi dicapai selama waktu penurunan 4 bulan.
\end{abstract}




\title{
DESAIN DAN SIMULASI TUNGKU BAKAR UNTUK PENGOLAHAN PASIR BESI MENJ ADI SPONGE IRON DE NG AN TEKNOLOGI TUNNEL KILN
}

\author{
Barman Tambunan, Cuk Supriyadi, J uliansyah
}

\begin{abstract}
Abstrak
Pasir besi merupakan salah satu potensi sumber daya alam yang tersebar di wilayah Indonesia. Pasir besi umumnya berupa magnetite (Fe3O4) dan hematite (Fe2O3) dengan kandungan pengotor berupa silica, alumina, dan titanium oksida. Untuk menaikkan nilai pasir besi, penelitian ini mengajukan tahapan proses antara lain proses benefisiasi dan proses reduksi menggunakan tungku bakar dengan teknologi Tunnel Kiln. Untuk mendapatkan proses reduksi yang optimal, dilakukan proses desain dan simulasi tungku bakar baik secara struktur maupun aliran fluida panas (Computional Fluid Dynamics/CFD). Penelitian ini menggunakan sampel pasir besi yang berasal dari kawasan pantai selatan pulau Jawa, yaitu Jawa bagian timur (lumajang), Jawa bagian tengah (Jogja) dan Jawa bagian Barat (Cipatujah). Untuk mengetahui performa hasil desain dan simulasi, dilakukan proses reduksi dengan menggunakan tungku bakar sesuai dengan desain. Performa hasil proses reduksi menghasilkan produk akhir Sponge Iron dengan kadar Fe 51.72\% menjadi $78.79 \%$ dengan derajat metalisasi $36.68 \%$ (sampel Jogja) dan dari $52.93 \%$ menjadi $57.90 \%$ dengan derajat metalisasi $24.43 \%$ (sampel Lumajang). Dari hasil tersebut membuktikan bahwa tungku bakar dengan teknologi Tunnel Kiln ini dapat meningkatkan nilai tambah Pasir besi.
\end{abstract}

Kata Kunci : Pasir besi, Desain, Simulasi, Tunnel Kiln, Sponge Iron

\section{KAJ IAN TEKNOLOGI PROSES PEMBUATAN GAS SINTETIK DARI BATUBARA DAN PROSPEK PEMANFAATAN PADA INDUSTRI HILIRNYA}

\author{
Muslim Efendi Harahap, Endro Wahju Tjahjono
}

\begin{abstract}
Abstrak
Potensi cadangan batubara di Indonesia sangat melimpah, namun yang menjadi isu utama adalah pemanfaatannya di Indonesia masih belum optimal. Salah satu alternatif pemanfaatan batubara tersebut adalah dengan mengkonversi batubara tersebut menjadi gas sintetik (syngas) yang kandungan utamanya adalah Hidrogen $\left(\mathrm{H}_{2}\right)$ dan Karbon Monoksida (CO). Untuk membuat gas sintetik dari batubara ini ada 4 macam teknologi proses yang telah dikenal di dunia yaitu Fixed-bed gasifier, Fluidized-bed gasifier, Entrained-bed gasifier dan Molten bath gasifier. Ada 3 jenis industri kimia yang dapat memanfaatkan gas sintetik ini sebagai alternatif bahan bakunya yaitu industri metanol, industri asam formiat dan industri amonia. Saat ini mereka menggunakan gas alam sebagai bahan bakunya. Semakin meluasnya penggunaan gas alam untuk berbagai macam kebutuhan dapat menyebabkan pasokan gas alam untuk ketiga jenis industri ini terganggu di kemudian hari. Oleh karena itu gas sintetik ini dapat dimanfaatkan sebagai alternatif pasokan bahan baku untuk ketiga jenis industri kimia tersebut kedepannya.
\end{abstract}

Kata kunci : Gas sintetis, fixed bed gasifier, fluidized bed gasifier, entrained bed gasifier dan molten bath gasifier, industri kimia 